\title{
Diagnostic accuracy of eFAST in the trauma patient: a systematic review and meta-analysis
}

\author{
Stuart Netherton, PhD, MD*; Velimir Milenkovic, MD+; Mark Taylor, MD*; Philip J. Davis, MD, MSc ${ }^{*}$
}

\section{CLINICIAN'S CAPSULE}

What is known about the topic?

Published studies demonstrate a wide range of sensitivities and specificities for the various components of the eFAST scan in trauma.

What did this study ask?

Through a systematic review process, we examined the pooled sensitivities and specificities for the components of an eFAST exam.

What did this study find?

The eFAST exam in trauma is helpful to rule in, but not to rule out, pneumothorax, pericardial effusion, and intra-abdominal free fluid.

Why does this study matter to clinicians?

An eFAST scan is an accepted part of the trauma assessment, and users should know the strengths and limitations of the test.

\section{ABSTRACT}

Objectives: Performing an extended Focused Assessment with Sonography in Trauma (eFAST) exam is common practice in the initial assessment of trauma patients. The objective of this study was to systematically review the published literature on diagnostic accuracy of all components of the eFAST exam. Methods: We searched Medline and Embase from inception through October 2018, for diagnostic studies examining the sensitivity and specificity of the eFAST exam. After removal of duplicates, 767 records remained for screening, of which 119 underwent full text review. Meta-DiSc ${ }^{\mathrm{TM}}$ software was used to create pooled sensitivities and specificities for included studies. Study quality was assessed using the Quality in Prognostic Studies (QUADAS-2) tool.

Results: Seventy-five studies representing 24,350 patients satisfied our selection criteria. Studies were published between 1989 and 2017. Pooled sensitivities and specificities were calculated for the detection of pneumothorax $169 \%$ and $99 \%$ respectively), pericardial effusion ( $91 \%$ and $94 \%$ respectively), and intra-abdominal free fluid ( $74 \%$ and $98 \%$ respectively). Sub-group analysis was completed for detection of intraabdominal free fluid in hypotensive (sensitivity $74 \%$ and specificity $95 \%$ ), adult normotensive (sensitivity $76 \%$ and specificity $98 \%$ ) and pediatric patients (sensitivity $71 \%$ and specificity 95\%).

Conclusions: Our systematic review and meta-analysis suggests that e-FAST is a useful bedside tool for ruling in pneumothorax, pericardial effusion, and intra-abdominal free fluid in the trauma setting. Its usefulness as a rule-out tool is not supported by these results.

\section{RÉSUMÉ}

Objectif: Le recours à l'évaluation ciblée par échographie étendue en traumatologie (eFAST : sigle anglais) est pratique courante dans l'évaluation initiale des patients ayant subi un trauma. L'étude avait donc pour but une revue systématique de la documentation publiée sur l'exactitude du diagnostic reposant sur tous les éléments constitutifs de l'eFAST.

Méthode: Les chercheurs ont effectué une recherche d'études sur les examens de diagnostic ayant pour objets la sensibilité et la spécificité de l'eFAST, dans les bases de données Medline et Embase, depuis leur début respectif jusqu'à octobre 2018. Après le retrait des doubles, il restait 767 documents aux fins de sélection, dont 119 ont été soumis à un examen en texte intégral. Le logiciel Meta-DiSc ${ }^{\mathrm{MC}}$ a servi à établir la sensibilité et la spécificité globales des études retenues. Quant à la qualité des études, elle a été évaluée à l'aide de l'instrument Quality in Prognostic Studies (QUADAS-2).

Résultats: Au total, 75 études totalisant 24350 patients et publiées entre 1989 et 2017 répondaient aux critères de sélection. La sensibilité et la spécificité globales ont été calculées pour la détection des pneumothorax (69\% et $99 \%$ respectivement), des épanchements péricardiques $(91 \%$ et $94 \%$ respectivement) et de liquide libre intra-abdominal ( $74 \%$ et $98 \%$ respectivement). II y a eu également analyse de sous-groupes en vue de la détection de liquide libre intra-abdominal chez les patients hypotendus (sensibilité : $74 \%$; spécificité : $95 \%$ ), les

\footnotetext{
*Department of Emergency Medicine, University of Saskatchewan, Saskatoon, SK; and the TDepartment of Surgery, University of Saskatchewan,
} Saskatoon, SK.

Correspondence to: Dr. Stuart J. Netherton, 103 Hospital Drive, Royal University Hospital, Saskatoon, SK, S7N 0W8; Email: stuartnetherton @ gmail. com 
adultes normotendus (sensibilité : $76 \%$; spécificité : $98 \%$ ) et les enfants (sensibilité : 71\%; spécificité : 95\%).

Conclusion: D'après les résultats de la revue systématique et de la méta-analyse, l'eFAST au chevet se montre utile pour confirmer la présence de pneumothorax, d'épanchement péricardique ou de liquide libre intra-abdominal en traumatologie, mais pas pour en écarter la présence.

Keywords: Emergency medicine, trauma, ultrasound

\section{BACKGROUND}

Traumatic injuries are the most common cause of morbidity and premature mortality in young adults, and the incidence of trauma presentations with a high injury severity is increasing over time..$^{1-3}$

The extended Focused Assessment with Sonography in Trauma (eFAST) exam is an accepted part of the trauma assessment ${ }^{4,5}$ and can be used to identify pneumothorax (PTX), pericardial effusions (PCE), and intra-abdominal free fluid (FF). ${ }^{6}$ Early detection of these findings can help clinicians prioritize the performance of further diagnostic and therapeutic interventions. ${ }^{6,7}$

Multiple studies have examined the use of ultrasound in the trauma setting, with variable reported sensitivities and specificities. 8 Prior reviews have used dated gold standards, ${ }^{10}$ limited ultrasound use to surgeons, ${ }^{11}$ or studied components of the eFAST in the pre-hospital setting. ${ }^{12,13}$ Two recent reviews ${ }^{14,15}$ examined the accuracy of an ultrasound for a patient with trauma, but no comprehensive systematic review has been performed examining the accuracy of all components of the eFAST exam. As such, we sought to determine the diagnostic accuracy of the eFAST exam for the detection of PTX, PCE, and FF in the undifferentiated trauma patient.

\section{METHODS}

We adhered to the Preferred Reporting Items for Systematic Reviews and Meta-Analyses (PRISMA) while undertaking this review. ${ }^{16}$

\section{Search strategy}

In collaboration with an expert librarian at the University of Saskatchewan, a search strategy was developed to search Embase and MEDLINE since inception (see
Appendix One). Search terms (medical subject, Emtree headings, and free text words) related to trauma patients; bedside ultrasound; and the detection of PTX, PCE, and FF were combined using Boolean Logic. The search was initially performed on August 29, 2017, and was updated on October 19, 2018. No age or language restrictions were applied.

\section{Study selection}

Search results were combined using Covidence ${ }^{\mathrm{TM}}$ Software (www.covidence.org), and duplicates were removed. Titles and abstracts were initially screened for inclusion by two independent reviewers ( $\mathrm{SN}$ and $\mathrm{VM}$ ) prior to a full-text review. Bibliographies of all included studies were also reviewed.

Our population of interest was trauma patients (blunt, penetrating, or polytrauma), who were assessed in an emergency department (ED) or trauma centre, underwent an ultrasound examination during their initial assessment, and subsequently had a gold standard test performed. The ultrasound was considered positive for PTX if a lung point or lack of a lung slide was seen. Hypoechoic fluid in the appropriate anatomic location was considered a positive ultrasound scan for PCE or FF. These definitions of positive scans were consistent across the included studies. Pelvic assessments for FF were not included. The gold standard comparator for PTX was a computed tomography (CT) scan or gush of air with chest tube insertion. For FF, the gold standard was positive laparotomy findings, diagnostic peritoneal lavage/aspirate (DPL/DPA), or CT scan; for PCE, it was a CT scan or positive intra-operative findings. Disagreements regarding study inclusion were resolved by consensus, and, if consensus could not be achieved, a third independent reviewer (PD) adjudicated. For studies published in a foreign language, study authors were contacted for an English translation of their work, and, if not available, a translation attempt was made using an online translation program (Google Translate ${ }^{\mathrm{TM}}$ ). 


\section{Outcomes of interest}

The primary outcome of interest was the sensitivity and specificity of eFAST. For inclusion, studies were required to have sensitivities and specificities expressed in a $2 \times 2$ table or to have provided enough information for the creation of a $2 \times 2$ table. Studies were excluded if they were performed in the wrong setting (prehospital), involved the wrong population (non-trauma), did not have an abovementioned gold standard comparator, or had incomplete data. All study designs were included except case reports and case series.

A subgroup analysis was planned for pregnant, geriatric, pediatric, and hypotensive trauma patients. Because of a paucity of available literature, the subgroup analysis was only possible for $\mathrm{FF}$ in pediatric and hypotensive patients. Because of high heterogeneity, a subgroup analysis of $\mathrm{FF}$ in adult normotensive patients was also performed.

\section{Critical appraisal of included studies}

Risk of bias (ROB) was evaluated by two independent reviewers (SN and VM) using the Quality Assessment of Diagnostic Accuracy Studies (QUADAS 2) tool. ${ }^{17}$ This tool examines the ROB in four domains: 1) patient selection; 2) the index test (ultrasound); 3) the reference standards (appropriate gold standard); and 4) timing and flow. Please see Appendix 2 for further information on the ROB domains and applicability concerns for all included studies, as well as the prompting questions used for this analysis.

\section{Data extraction}

Data were extracted using a piloted data extraction form by two independent reviewers (SN and VM). If discrepancies arose, an attempt at consensus was made, and, if consensus could not be reached, a third reviewer (PD) adjudicated. Extracted information included: gold standard test, study design, patient characteristics (age and gender), type of trauma, true positives, true negatives, false positives, and false negatives for an ultrasound while investigating for the presence of PTX, PCE, or FF.

\section{Data synthesis}

Data were compiled using Meta-DiSc ${ }^{\mathrm{TM}}$ software $^{18}$ and subsequently analyzed in collaboration with a statistician at the Clinical Research Support Unit (CRSU) at the University of Saskatchewan. A bivariate random effect model was used for generating pooled sensitivities, specificities, and positive and negative likelihood ratios.

\section{RESULTS}

After removing duplicates, our search strategy yielded 767 articles. After a title and abstract screen, 119 publications underwent a full-text review, of which 71 papers met the inclusion criteria. An additional four papers were added from the bibliographic review, representing a total of 75 included studies (Appendix 3). Seventeen of the included studies examined the eFAST detection of PTX (Appendix 4), nine studies considered the detection of PCE (Appendix 5), and 52 examined the detection of FF (Appendix 6).

\section{PTX}

Table 1 summarizes the patient characteristics and study outcomes of the 17 included studies examining the use of ultrasound for the identification of PTX. These studies included a total of 3653 patients. Five of the studies (as indicated in Table 1) considered each lung as a data point, meaning that each patient provided up to two data points. All studies combined provided 4816 data points. The average age was 39.8 years, $75 \%$ of the patients were male, and the predominating injury occurred through a blunt mechanism. Pooled sensitivity (Figure 1a) was 0.694 (95\% confidence interval [CI] $\left.0.660-0.727 ; \quad \mathrm{I}^{2}=91 \%\right), \quad$ and pooled specificity (Figure 1b) was 0.99 (95\% CI 0.99-0.99; $\mathrm{I}^{2}=66.9 \%$ ), with high heterogeneity amongst included studies (see Figure 1a and b). The area under the curve (AUC) for the summary receiver operating characteristic (sROC) curve was 0.994 (Appendix 7), and the pooled accuracy was 0.943 . Appendix 10 summarizes the ROB for the included studies. Overall, the ROB for the studies investigating PTX was low to moderate, with all bias largely coming from patient selection (Kappa values, as indicated in Appendix 3).

\section{PCE}

Table 2 summarizes patient characteristics and study outcomes from the nine studies examining the use of ultrasound for identification of PCE. These studies 
Table 1. Patient characteristics and study outcomes of the 17 included studies examining the use of ultrasound for identification of PTX.

\begin{tabular}{|c|c|c|c|c|c|c|c|c|c|c|c|}
\hline Author* ${ }^{*}$ & Year & Location & $\mathrm{N}$-value & $\begin{array}{l}\text { No. } \\
\text { patients }\end{array}$ & $\begin{array}{l}\# \\
\text { TP }\end{array}$ & Type of trauma & Study design & Sensitivity & Specificity & $+\mathrm{LR}$ & $-L R$ \\
\hline Blaivas & 2005 & Augusta, USA & 176 & 176 & 53 & Blunt & Prospective & 0.98 & 0.99 & 119.74 & 0.02 \\
\hline Kaya & 2015 & Eskisehir, Turkey & 212 & 212 & 22 & Blunt & Prospective & 0.88 & 0.99 & 164.56 & 0.12 \\
\hline Abbasi & 2013 & Tehran, Iran & 146 & 146 & 32 & $\begin{array}{l}\text { Blunt, penetrating, and } \\
\text { polytrauma }\end{array}$ & Prospective & 0.86 & 1.00 & 188.16 & 0.14 \\
\hline Soult & 2015 & Norfolk, USA & 345 & 345 & 27 & Blunt and penetrating & Retrospective & 0.40 & 0.99 & 54.99 & 0.61 \\
\hline $\mathrm{Ku}$ & 2013 & Philadelphia, USA & 549 & 549 & 27 & Blunt and penetrating & Prospective & 0.57 & 0.99 & 96.13 & 0.43 \\
\hline Helland & 2016 & Chicago, USA & 260 & 260 & 33 & Blunt & Prospective & 0.67 & 1.00 & 284.08 & 0.33 \\
\hline Hyacinthe & 2012 & Grenoble, France & 273 & 136 & 28 & Blunt and penetrating & Prospective & 0.53 & 0.95 & 10.57 & 0.48 \\
\hline Nandipati & 2010 & $\begin{array}{l}\text { New York City, } \\
\text { USA }\end{array}$ & 205 & 205 & 20 & Blunt and penetrating & Prospective & 0.95 & 0.99 & 175.24 & 0.05 \\
\hline Brook & 2009 & Haifa, Israel & 172 & 172 & 20 & Not given & Prospective & 0.47 & 0.98 & 20.00 & 0.55 \\
\hline Kirkpatrick & 2004 & $\begin{array}{l}\text { Vancouver, } \\
\text { Canada }\end{array}$ & 467 & 233 & 33 & Blunt and penetrating & Prospective & 0.59 & 0.99 & 80.73 & 0.41 \\
\hline Soldati & 2008 & Multicenter, Italy & 218 & 109 & 23 & Blunt and penetrating & Prospective & 0.92 & 0.99 & 177.56 & 0.08 \\
\hline Abdulrahman & 2014 & Doha, Qatar & 610 & 305 & 32 & Blunt & Prospective & 0.43 & 0.98 & 22.83 & 0.58 \\
\hline lanniello & 2014 & Rome, Italy & 756 & 378 & 67 & Not given & Retrospective & 0.77 & 1.00 & 515.21 & 0.23 \\
\hline Nagarsheth & 2011 & Knoxville, TN & 79 & 79 & 18 & Blunt and penetrating & Prospective & 0.82 & 1.00 & 93.30 & 0.18 \\
\hline Zhang & 2006 & Hangzhou, China & 135 & 135 & 25 & Blunt & Prospective & 0.86 & 0.97 & 30.46 & 0.14 \\
\hline Soldati & 2006 & Multicenter, Italy & 186 & 186 & 55 & Blunt & Prospective & 0.98 & 1.00 & 255.11 & 0.02 \\
\hline \multirow[t]{3}{*}{ Rowan } & 2002 & $\begin{array}{l}\text { Vancouver, } \\
\text { Canada }\end{array}$ & 27 & 27 & 11 & Blunt & Prospective & 1.00 & 0.94 & 16.00 & 0.05 \\
\hline & & & & & & & Pooled: & 0.69 & 0.99 & 62.58 & 0.26 \\
\hline & & & & & & & $\begin{array}{l}\text { 95\% confidence } \\
\text { interval: }\end{array}$ & $0.66-0.73$ & $0.98-0.99$ & $32.7-119.7$ & $0.18-0.36$ \\
\hline
\end{tabular}


(a)

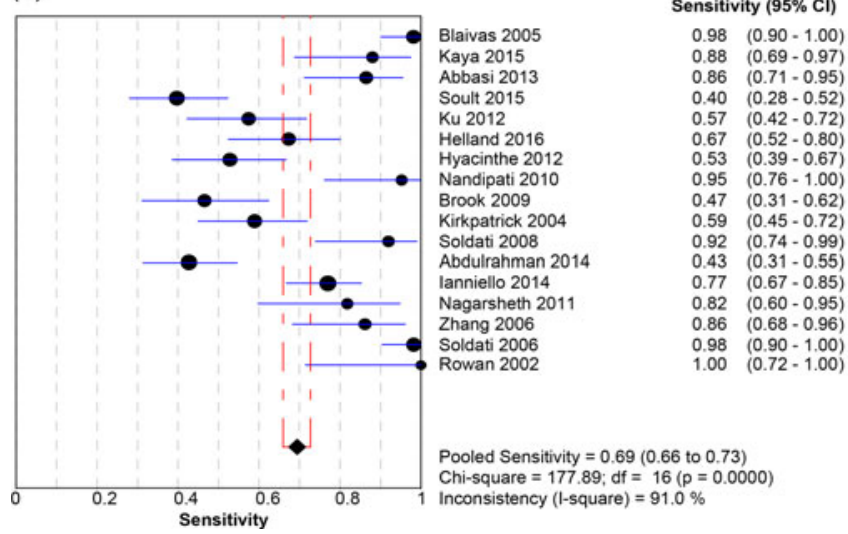

(b)

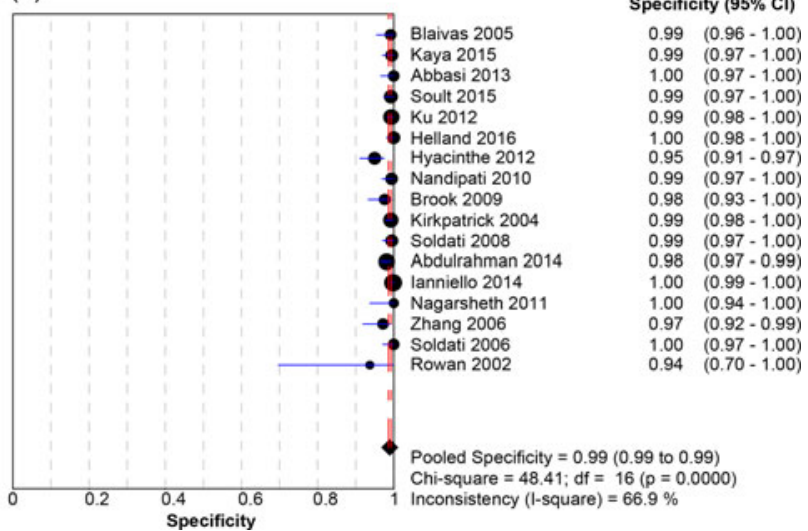

Figure 1. Forest plot displaying the sensitivity (a) and specificity (b) of the included studies for ultrasound identification of PTX in trauma patients.

included a total of 1,031 patients and included only penetrating trauma. The average patient age was 30 years, with a male predominance (86\%). Appendix 10 summarizes the ROB and concerns for applicability for all included studies. These studies averaged a low to moderate $\mathrm{ROB}$, with all bias arising solely from factors involved with patient selection (Kappa values, as indicated in Appendix 3). The pooled sensitivity (Figure 2a) was 0.912 (95\% CI $0.870-0.944 ; \mathrm{I}^{2}=65.6 \%$ ), and pooled specificity (Figure 2b) was 0.941 (95\% CI 0.922-0.957; $\mathrm{I}^{2}=96.6 \%$ ), with high heterogeneity amongst the included studies (see Figure $2 \mathrm{a}$ and $\mathrm{b}$ ). The AUC of the sROC curve (Appendix 8) was 0.975, and the pooled accuracy was 0.934 . There were two studies that presented significant outlying results. ${ }^{19,20}$ Further, a sensitivity analysis with these two studies removed yielded a sensitivity of $0.982\left(95 \%\right.$ CI $\left.0.937-0.998 ; \mathrm{I}^{2}=0 \%\right)$ and specificity of 0.985 (95\% CI $\left.0.973-0.992 ; \mathrm{I}^{2}=66.8 \%\right)$.

\section{Intra-abdominal FF}

Table 3 summarizes the patient characteristics and study outcomes of the 52 included studies examining the use of ultrasound for the identification of FF. These studies

\begin{tabular}{|c|c|c|c|c|c|c|c|c|c|c|}
\hline Author* & Year & Location & $\begin{array}{l}\text { No. of } \\
\text { patients }\end{array}$ & $\begin{array}{l}\# \\
\mathrm{TP}\end{array}$ & $\begin{array}{l}\text { Type of } \\
\text { trauma }\end{array}$ & Study design & Sensitivity & Specificity & $+\mathrm{LR}$ & $-L R$ \\
\hline Carillo & 2000 & Louisville, USA & 31 & 9 & Penetrating & Prospective & 1.00 & 1.00 & 43.70 & 0.05 \\
\hline Matsushima & 2017 & $\begin{array}{l}\text { Los Angeles, } \\
\text { USA }\end{array}$ & 103 & 12 & Penetrating & Retrospective & 0.92 & 0.96 & 20.77 & 0.08 \\
\hline Rozycki & 1999 & $\begin{array}{l}\text { multicenter, } \\
\text { USA }\end{array}$ & 261 & 29 & Penetrating & Prospective & 1.00 & 0.97 & 30.55 & 0.02 \\
\hline Tayal & 2003 & Charlotte, USA & 32 & 8 & Penetrating & Prospective & 1.00 & 1.00 & 47.22 & 0.06 \\
\hline Nagy & 1995 & Chicago, USA & 122 & 30 & Penetrating & Retrospective & 0.97 & 1.00 & 175.37 & 0.05 \\
\hline Nicol & 2015 & $\begin{array}{l}\text { Cape Town, } \\
\text { South Africa }\end{array}$ & 172 & 117 & Penetrating & Prospective & 0.87 & 0.05 & 0.92 & 2.47 \\
\hline Rozycki & 1996 & Atlanta, USA & 246 & 10 & Penetrating & Prospective & 1.00 & 1.00 & 452.45 & 0.05 \\
\hline Varin & 2009 & $\begin{array}{l}\text { Rotterdam, } \\
\text { Netherlands }\end{array}$ & 30 & 12 & Penetrating & Retrospective & 1.00 & 1.00 & 36.54 & 0.04 \\
\hline \multirow[t]{3}{*}{ Boulanger } & 2001 & Lexington, USA & 34 & 1 & Penetrating & Prospective & 0.33 & 1.00 & 24.00 & 0.67 \\
\hline & & & & & & Pooled: & 0.91 & 0.94 & 34.17 & 0.11 \\
\hline & & & & & & $\begin{array}{l}95 \% \text { confidence } \\
\text { interval }\end{array}$ & $0.87-0.94$ & $0.92-0.96$ & $0.9-1308$ & $0.03-0.47$ \\
\hline
\end{tabular}


(a)

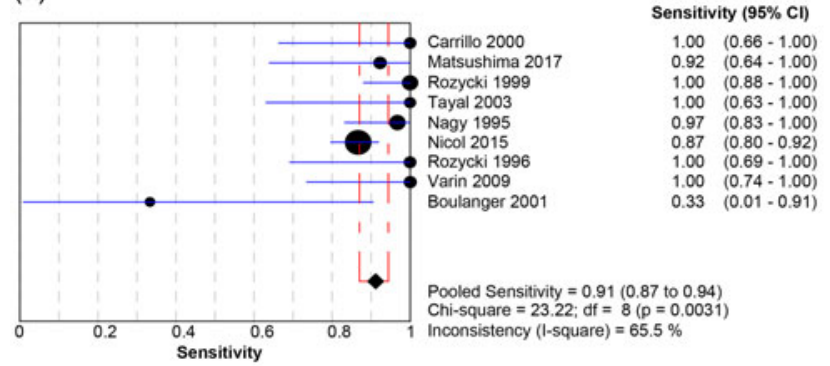

(b)

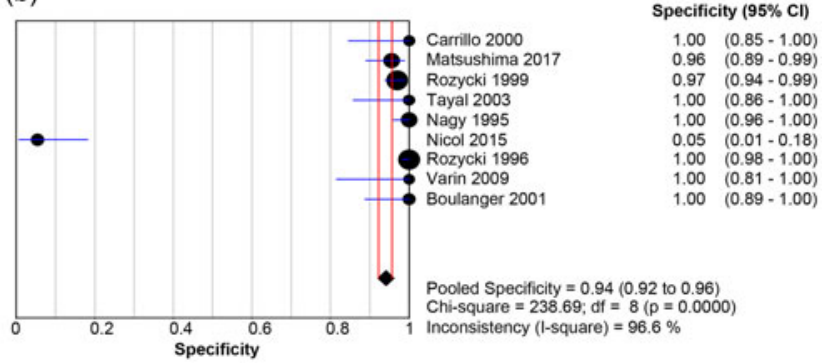

Figure 2. Forest plot displaying the sensitivity (a) and specificity (b) of the included studies for ultrasound identification of PCE in trauma patients.

included a total of 19,666 patients, with an average age of 33.3 years, of whom $68.4 \%$ were male. One study ${ }^{21}$ examined only pregnant trauma patients, of whom $46 \%$, were in their third trimester. Six studies included only pediatric patients. ${ }^{22-27}$ Eight additional studies included patients of all ages (pediatric and adult) but did not stratify patients based on age. ${ }^{28-35}$ Five papers included only hypotensive patients (systolic blood pressure $[\mathrm{sBP}]$ of $<90 \mathrm{~mm} \mathrm{Hg})^{28,36-39}$ One study ${ }^{40}$ compared both a hand-held ultrasound machine and a regular ultrasound machine against the gold standard, providing two sets of data from one paper.

Appendix 10 summarizes the ROB for all included studies. Overall, the ROB was low to moderate. Both patient selection and flow and timing factored into the overall bias assessment of these papers (Kappa values, as indicated in Appendix 3). The pooled sensitivity (Figure 3a) was 0.742 (95\% CI $0.726-0.758 ; \mathrm{I}^{2}=$ $82.7 \%$ ), and the pooled specificity (Figure $3 \mathrm{~b}$ ) was 0.976 (95\% CI $0.973-0.978 ; \mathrm{I}^{2}=83 \%$ ), with high heterogeneity amongst the included studies (see Figure 3a and b). The AUC of the sROC curve (Appendix 9) was 0.931 , and the overall pooled accuracy was 0.942 .

If only pediatric patients were considered, the pooled sensitivity was 0.709 (95\% CI $0.615-0.792 ; \mathrm{I}^{2}=68.1 \%$ ) and the pooled specificity was 0.951 (95\% CI $0.933-$ $\left.0.965 ; \mathrm{I}^{2}=72.1 \%\right) .{ }^{22-27}$ The pooled positive likelihood ratio was 14.13 (95\% CI $\left.6.533-30.567 ; \mathrm{I}^{2}=70.9 \%\right)$. The pooled negative likelihood ratio was 0.32 (95\% CI $\left.0.193-0.535 ; \mathrm{I}^{2}=62.6 \%\right)$. The AUC of the sROC curve was 0.959 , and the pooled accuracy from these studies was calculated to be 0.92 .

Among studies examining only hypotensive patients $(\mathrm{sBP}<90 \mathrm{~mm} \mathrm{Hg}),{ }^{28,36-39}$ and the pooled sensitivity was 0.743 (95\% CI $\left.0.681-0.799 ; \mathrm{I}^{2}=38.7 \%\right)$. The pooled specificity was 0.949 (95\% CI $0.926-0.966$;
$\left.\mathrm{I}^{2}=41.5 \%\right)$. The pooled positive likelihood ratio was 11.87 (95\% CI 5.864-24.056; $\mathrm{I}^{2}=60.1 \%$ ). The pooled negative likelihood ratio was 0.30 (95\% CI 0.214 $\left.0.423 ; \mathrm{I}^{2}=48.7 \%\right)$. The AUC of the sROC curve was 0.856 , and the pooled accuracy from these studies was calculated to be 0.888 .

Among studies examining only adult normotensive patients, the pooled sensitivity was 0.76 (95\% CI $\left.0.739-0.781 ; \mathrm{I}^{2}=84.7\right)$. The pooled specificity was 0.98 (95\% CI $0.975-0.981 ; \mathrm{I}^{2}=85.4 \%$ ). The pooled positive likelihood ratio was 33.5 (95\% CI 23.354-48.121; $\mathrm{I}^{2}=$ $80.1 \%$ ), and the pooled negative likelihood ratio was 0.231 (95\% CI 0.176-0.304; $\mathrm{I}^{2}=90.3 \%$ ). The AUC of the sROC curve was 0.946 , and the pooled accuracy from these studies was calculated to be 0.949 .

\section{DISCUSSION}

The undifferentiated trauma patient can present several simultaneous diagnostic and disposition challenges. The eFAST exam provides trauma practitioners with a bedside tool that can provide adjunctive information to the primary survey and help prioritize care.

Two recent reviews evaluated components of the eFAST exam, and although methodologically different from this review, they reach similar conclusions. ${ }^{14,15}$ Staub et al. investigated detection of both PTX and hemothorax (which was not a focus of this review) and reported a sensitivity of $81 \%$, a specificity of $98 \%$, and an AUC of 0.979 for ultrasound detection of PTX that is very similar to the one presented here $(0.994$, Appendix 7).

Stengel et al. ${ }^{15}$ examined the use of ultrasound in blunt thoracoabdominal trauma patients. Their analysis had two subgroups: 1) all abdominal injury (FF, organ 


\begin{tabular}{|c|c|c|c|c|c|c|c|c|c|c|}
\hline Author & Year & Location & $\begin{array}{l}\text { No. } \\
\text { patients }\end{array}$ & $\begin{array}{l}\# \\
\text { TP }\end{array}$ & $\begin{array}{l}\text { Type of } \\
\text { trauma }\end{array}$ & Study design & Sensitivity & Specificity & $+L R$ & $-L R$ \\
\hline Holmes & 2004 & $\begin{array}{l}\text { Sacremento, } \\
\text { USA }\end{array}$ & 447 & 92 & Blunt & Retrospective & 0.79 & 0.95 & 17.50 & 0.22 \\
\hline McGahan & 1997 & $\begin{array}{l}\text { Sacramento, } \\
\text { USA }\end{array}$ & 121 & 24 & Blunt & Prospective & 0.63 & 0.95 & 13.11 & 0.39 \\
\hline Massarutti & 2004 & Udine, Italy & 40 & 7 & Blunt & Retrospective & 0.64 & 0.83 & 3.69 & 0.44 \\
\hline Waydhas & 1991 & $\begin{array}{l}\text { Munich, } \\
\text { Germany }\end{array}$ & 64 & 17 & Blunt & Prospective & 0.74 & 0.95 & 15.15 & 0.27 \\
\hline Niebuhr & 1992 & $\begin{array}{l}\text { Heidberg, } \\
\text { Germany }\end{array}$ & 233 & 27 & $\begin{array}{l}\text { Blunt and } \\
\text { polytrauma }\end{array}$ & Prospective & 0.96 & 1.00 & 390.69 & 0.05 \\
\hline Gaarder & 2009 & Oslo, Norway & 104 & 16 & $\begin{array}{l}\text { Blunt and } \\
\text { penetrating }\end{array}$ & Prospective & 0.62 & 0.96 & 16.00 & 0.40 \\
\hline Nural & 2005 & $\begin{array}{l}\text { Samsun, } \\
\text { Turkey }\end{array}$ & 454 & 32 & Blunt & Retrospective & 0.86 & 0.95 & 18.98 & 0.14 \\
\hline Nunes & 2001 & $\begin{array}{l}\text { Philadelphia, } \\
\text { USA }\end{array}$ & 147 & 9 & $\begin{array}{l}\text { Blunt, } \\
\text { penetrating, } \\
\text { and } \\
\text { polytrauma }\end{array}$ & Prospective & 0.69 & 1.00 & 183.21 & 0.32 \\
\hline Udobi & 2001 & Baltimore, USA & 75 & 19 & Penetrating & Prospective & 0.59 & 0.95 & 12.77 & 0.43 \\
\hline Boulanger & 2001 & Lexington, USA & 66 & 12 & Penetrating & Prospective & 0.67 & 0.98 & 32.00 & 0.34 \\
\hline Salera & 2005 & Ancona, Italy & 621 & 68 & Blunt & Retrospective & 0.88 & 0.99 & 96.08 & 0.12 \\
\hline Wherrett & 1996 & $\begin{array}{l}\text { Toronto, } \\
\text { Canada }\end{array}$ & 69 & 17 & Blunt & Prospective & 0.85 & 0.90 & 8.33 & 0.17 \\
\hline Varin & 2009 & $\begin{array}{l}\text { Rotterdam, } \\
\text { Netherlands }\end{array}$ & 229 & 44 & Penetrating & Retrospective & 0.65 & 0.98 & 26.04 & 0.36 \\
\hline Miller & 2003 & $\begin{array}{l}\text { Allentown, } \\
\text { USA }\end{array}$ & 359 & 16 & Blunt & Prospective & 0.42 & 0.98 & 16.89 & 0.59 \\
\hline Richards & 2004 & $\begin{array}{l}\text { Sacramento, } \\
\text { USA }\end{array}$ & 4320 & 409 & Blunt & Prospective & 0.69 & 0.98 & 29.04 & 0.32 \\
\hline Ma & 1995 & $\begin{array}{c}\text { Milwaukee, } \\
\text { USA }\end{array}$ & 245 & 32 & $\begin{array}{l}\text { Blunt and } \\
\text { penetrating }\end{array}$ & Retrospective & 0.86 & 1.00 & 179.89 & 0.14 \\
\hline Kimura & 1991 & Tokyo, Japan & 72 & 13 & Blunt & Prospective & 0.87 & 1.00 & 97.88 & 0.13 \\
\hline Jehle & 1993 & Buffalo, USA & 44 & 9 & Blunt & Retrospective & 0.82 & 0.94 & 13.50 & 0.19 \\
\hline Hoffman & 2009 & Omaha, USA & 458 & 80 & Blunt & Retrospective & 0.58 & 0.92 & 6.94 & 0.45 \\
\hline Brown & 2001 & $\begin{array}{l}\text { San Diego, } \\
\text { USA }\end{array}$ & 2693 & 145 & Blunt & Prospective & 0.84 & 0.96 & 23.10 & 0.16 \\
\hline Rozycki & 1993 & $\begin{array}{c}\text { Washington, } \\
\text { DC, USA }\end{array}$ & 476 & 71 & $\begin{array}{l}\text { Blunt and } \\
\text { penetrating }\end{array}$ & Prospective & 0.79 & 0.96 & 17.91 & 0.22 \\
\hline Brooks & 2004 & $\begin{array}{l}\text { Nottingham, } \\
\text { UK }\end{array}$ & 110 & 10 & $\begin{array}{l}\text { Blunt and } \\
\text { penetrating }\end{array}$ & Prospective & 0.77 & 0.99 & 75.38 & 0.23 \\
\hline Ruchholtz & 2004 & $\begin{array}{l}\text { Essen, } \\
\text { Germany }\end{array}$ & 80 & 30 & Blunt & Prospective & 0.75 & 0.98 & 30.00 & 0.26 \\
\hline Lingawi & 2000 & $\begin{array}{l}\text { Vancouver, } \\
\text { Canada }\end{array}$ & 1063 & 66 & Blunt & Retrospective & 0.94 & 0.98 & 49.28 & 0.06 \\
\hline $\mathrm{Hsu}$ & 2007 & $\begin{array}{l}\text { Sydney, } \\
\text { Australia }\end{array}$ & 410 & 78 & Blunt & Prospective & 0.78 & 0.97 & 30.23 & 0.23 \\
\hline Rothlin & 1993 & $\begin{array}{l}\text { Zurich, } \\
\text { Switzerland }\end{array}$ & 312 & 52 & Blunt & Prospective & 0.98 & 1.00 & 505.56 & 0.02 \\
\hline \multirow[t]{2}{*}{ Goodwin } & 2001 & $\begin{array}{l}\text { Sacramento, } \\
\text { USA }\end{array}$ & 126 & 5 & Blunt & Retrospective & 0.83 & 0.98 & 33.33 & 0.17 \\
\hline & & & & & & & & & & (Continued) \\
\hline
\end{tabular}


Stuart Netherton et al.

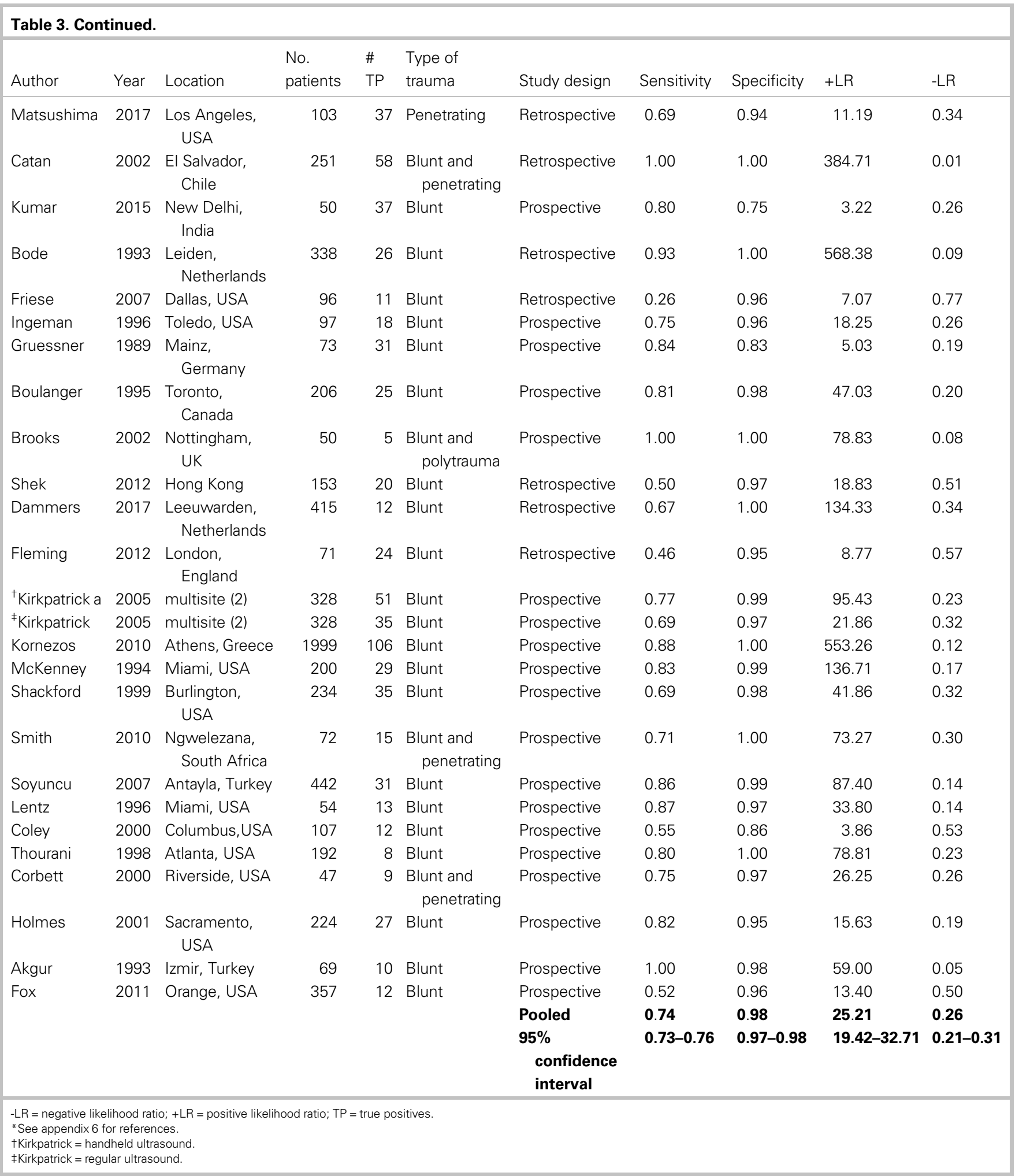


(a)

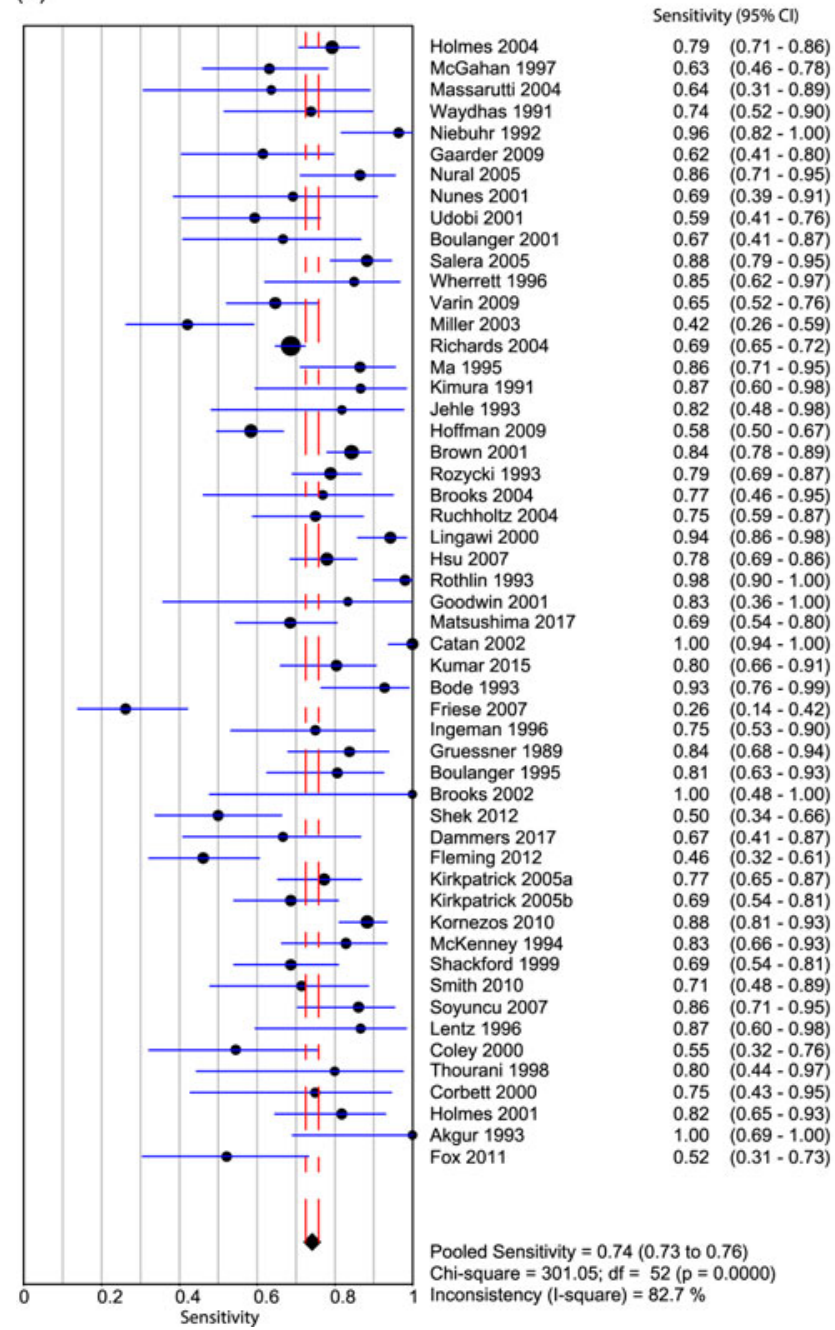

(b)

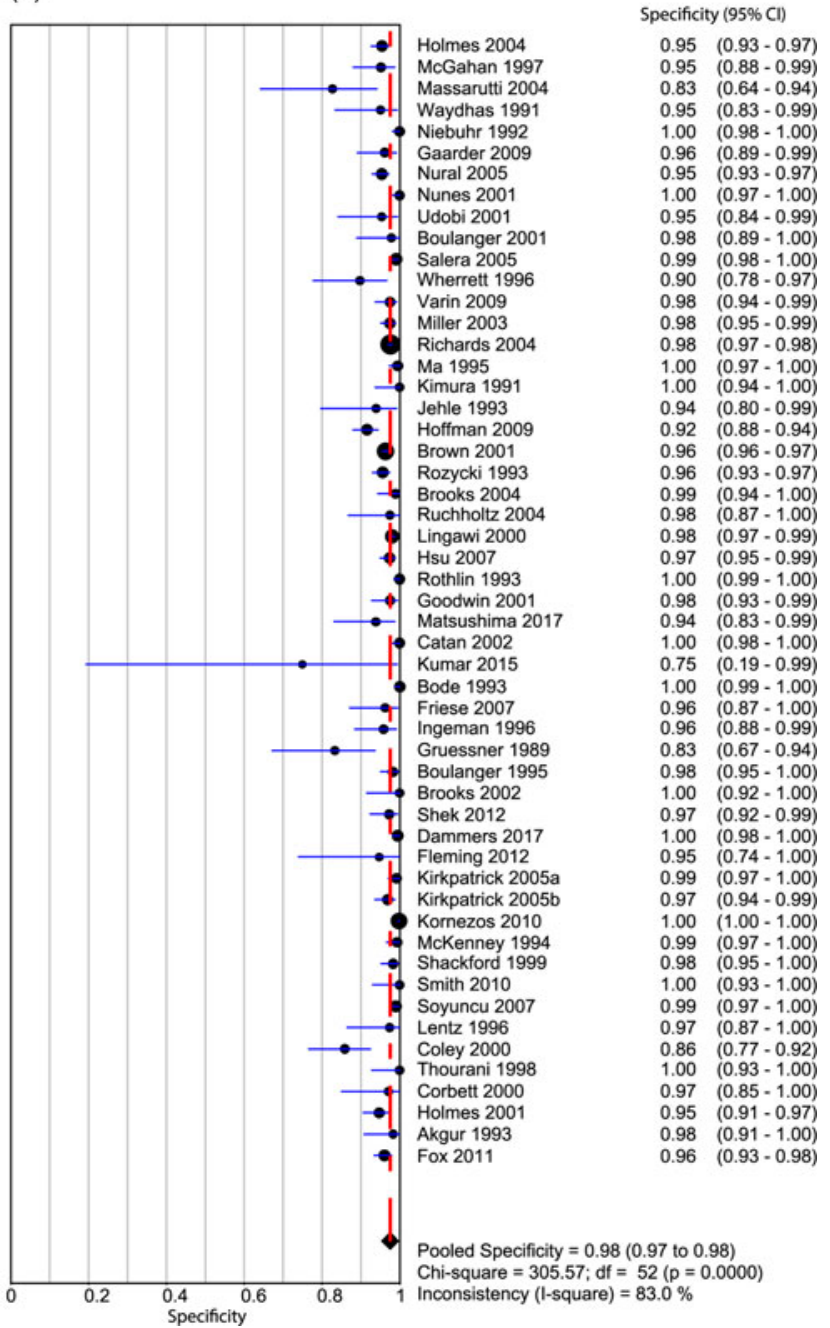

Figure 3. Forest plot displaying the sensitivity (a) and specificity (b) of the included studies for ultrasound identification of intra-abdominal FF in trauma patients.

injury, vascular injury; sensitivity $68 \%$ and specificity 95\%); or 2) abdominal FF and/or intra-abdominal free air (sensitivity $78 \%$ and specificity $97 \%$ ). Direct comparison to our review is difficult as we did not look at ultrasound use for the detection of free intra-abdominal air, organ injury, or vascular injury. In their thoracic group analysis, only four papers investigating the use of ultrasound in the detection of PTX's were included, making direct comparison difficult. Regardless of these differences, the reported sensitivities and specificities are very similar to our findings.

\section{Identification of pneumothorax}

Our results suggest a moderate sensitivity and good specificity in detecting PTX in the trauma setting, corresponding to a positive likelihood ratio of 62.57 and a negative likelihood ratio of 0.256 (Table 1). While our results suggest that the eFAST scan can be used as a rule-in test for the detection of PT, it lacks adequate sensitivity to be used as a rule-out test. Further, it should be noted, that depending on the patient's age and comorbidities, several false positives (e.g., prior pleurodesis and interstitial lung disease) and negatives (e.g., small PTX, and subcutaneous air) can occur. $^{41}$

A previous review from 2012 included eight studies examining ultrasound detection of PTX in traumatic and non-traumatic patients and suggested a similar specificity $(98.2 \%)$, with a much higher sensitivity of $90.9 \%$, however with significant heterogeneity. ${ }^{8}$ This discrepancy could be explained by technological improvements 
in the gold standard test and the increased frequency in the detection of occult pneumothoraces because of the increased use of CT.

A more recent 2018 systematic found a sensitivity of $81 \%$ and specificity of $98 \%$ in ultrasound detection of traumatic PTX. ${ }^{14}$ For various reasons, our review included different studies than Staub et al. Three papers included in our review, but not theirs, had sensitivities of $40 \%,{ }^{42} 43 \%,{ }^{5}$ and $77 \% .{ }^{43}$ The two papers not included herein but cited by the aforementioned review had sensitivities of $83 \%{ }^{44}$ and $95 \% .{ }^{45}$ These likely explain the sensitivity differences. However, whether having a sensitivity of $69 \%$ or $81 \%$, ultrasound still does not perform well enough to be used as a rule-out test.

\section{Identification of a PCE}

Our pooled results suggest excellent sensitivity and specificity of eFAST in the detection of a PCE in the trauma setting with a positive likelihood ratio of 34.169 and negative likelihood ratio of 0.110 (Table 2). Two papers ${ }^{19,20}$ presented outlying results, with one paper ${ }^{19}$ having a specificity of $5 \%$. While not directly commented upon in the original publication, this appears to be because of including only penetrating injuries to the cardiac box, which would have a high pretest probability of injury, resulting in few true negative scans and an overall low specificity. In the other study, only one true positive result was returned, ${ }^{20}$ limiting this study. Removal of these outlying papers from the analysis resulted in a sensitivity of $98.2 \%$ and specificity of $98.5 \%$. These adjusted results better reflect the summary of available literature. A false positive PCE scan can result from epicardial fat or pleural fluid, but false negatives can be because of small volumes of PCE or pericardial lacerations.

\section{Identification of free intra-abdominal fluid}

Our pooled results suggest a moderate sensitivity and excellent specificity of eFAST in the detection of FF corresponding to a positive likelihood ratio of 20.3 and negative likelihood ratio of 0.25 (Table 3). These test characteristics did not change significantly if pediatric, hypotensive, and adult normotensive subgroups were considered. If considering use, it should be noted again that there is the potential for false positives (e.g., perinephric fat and abdominal ascites) and false negatives (e.g., a small volume of fluid). Lastly, as there were high degrees of heterogeneity amongst included studies, clinician judgment should predominate while considering disposition based on ultrasound imaging.

\section{Limitations}

Our study had several potential limitations. First and foremost, our study was potentially limited by our search strategy. To minimize selection bias, we employed an expert librarian to develop our search strategy and used a bibliographic review of all included studies to minimize the chances of missing important literature. Given the moderate to high heterogeneity of included studies, it is unlikely that any missed studies would have dramatically changed our final results or conclusions. Further, our results are similar to two recent reviews. ${ }^{14,15}$

We recognize the potential for publication bias, as only positive results are generally published. However, some included papers report low sensitivities and specificities, and during the history of ultrasound literature, many groups investigated whether the technology would be of benefit that is reflected by the large heterogeneity of study results. Funnel plot analysis was performed for lung and abdominal exam aspects of the eFAST and did not show evidence of publication bias (data are not shown).

Thirdly, the quality of the included studies is always a concern in systematic reviews and meta-analyses. As with study quality, we are also unable to control the statistical heterogeneity of the presented studies, by which this study is limited. If compared to the entire group of studies examining FF, the subgroup analyses had similar results, yet improved heterogeneity. While the large group was heterogeneous, these similar results in the less heterogeneous subgroups provide some reassurance to our findings.

\section{CONCLUSIONS}

Our findings suggest that eFAST can be used as a rule-in test for PTX, FF, or PCE in a trauma setting. This is supported by the high specificities and high positive likelihood ratios for each scan. Its usefulness as a rule-out tool in the trauma setting is not supported by our findings.

\section{SUPPLEMENTARY MATERIAL}

The supplementary material for this article can be found at https://doi.org/10.1017/cem.2019.381. 


\section{REFERENCES}

1. Dutton RP, Stansbury LG, Leone S, et al. Trauma mortality in mature trauma systems: are we doing better? An analysis of trauma mortality patterns, 1997-2008. 7 Trauma 2010;69 (3):620-6.

2. Zakrison T, Ball CG, Kirkpatrick AW. Trauma in Canada: a spirit of equity \& collaboration. World 7 Surg 2013;37 (9):2086-93.

3. Berwick DM, Downey AS, Cornett EA. A national trauma care system to achieve zero preventable deaths after injury: recommendations from a national academies of sciences, engineering, and medicine report. $7 A M A$ 2016;316(9):927-8.

4. Kirkpatrick AW, Sirois M, Laupland KB, et al. Hand-held thoracic sonography for detecting post-traumatic pneumothoraces: the Extended Focused Assessment with Sonography for Trauma (EFAST). 7 Trauma 2004;57(2):288-95.

5. Abdulrahman Y, Musthafa S, Hakim SY, et al. Utility of extended FAST in blunt chest trauma: is it the time to be used in the ATLS algorithm? World 7 Surg 2015;39 (1):172-8.

6. Rippey JC, Royse AG. Ultrasound in trauma. Best Pract Res Clin Anaesthesiol 2009;23(3):343-62.

7. Rose JS. Ultrasound in abdominal trauma. Emerg Med Clin North Am 2004;22(3):581-99.

8. Alrajhi K, Woo MY, Vaillancourt C. Test characteristics of ultrasonography for the detection of pneumothorax: a systematic review and meta-analysis. Chest 2012;141(3):703-8.

9. Nishijima DK, Simel DL, Wisner DH, Holmes JF. Does this adult patient have a blunt intra-abdominal injury? $7 A M A$ 2012;307(14):1517-27.

10. Wilkerson RG, Stone MB; R.G. W. Sensitivity of bedside ultrasound and supine anteroposterior chest radiographs for the identification of pneumothorax after blunt trauma. Acad Emerg Med 2010;17(1):11-7.

11. Beggs AD, Thomas PR. Point of use ultrasound by general surgeons: review of the literature and suggestions for future practice. Int 7 Surg 2013;11(1):12-7.

12. Jørgensen H, Jensen CH, Dirks J. Does prehospital ultrasound improve treatment of the trauma patient? A systematic review. Eur 7 Emerg Med 2010;17(5):249-53.

13. O'Dochartaigh D, Douma M. Prehospital ultrasound of the abdomen and thorax changes trauma patient management: A systematic review. Injury 2015;46(11):2093-102.

14. Staub LJ, Biscaro RR, Kaszubowski E, Maurici R. Chest ultrasonography for the emergency diagnosis of traumatic pneumothorax and haemothorax: A systematic review and meta-analysis. Injury 2018;49(3):457-66.

15. Stengel D, Bauwens K, Sehouli J, et al. Systematic review and meta-analysis of emergency ultrasonography for blunt abdominal trauma. Br 7 Surg 2001;88(7):901-12.

16. Liberati A, Altman DG, Tetzlaff J, et al. The PRISMA statement for reporting systematic reviews and meta-analyses of studies that evaluate health care interventions: explanation and elaboration. 7 Clin Epidemiol 2009;62(10)e1-34.

17. Whiting PF, Rutjes AW, Westwood ME, et al. QUADAS-2: a revised tool for the quality assessment of diagnostic accuracy studies. Ann Intern Med 2011;155(8):529-36.
18. Zamora J, Abraira V, Muriel A, Khan K, Coomarasamy A. Meta-DiSc: a software for meta-analysis of test accuracy data. BMC Med Res Methodol 2006;6(1):31.

19. Nicol AJ, Navsaria PH, Beningfield S, Hommes M, Kahn D. Screening for occult penetrating cardiac injuries. Ann Surg 2015;261(3):573-8.

20. Boulanger BR, Kearney PA, Tsuei B, Ochoa JB. The routine use of sonography in penetrating torso injury is beneficial. $\mathcal{F}$ Trauma 2001;51(2):320-5.

21. Goodwin H, Holmes JF, Wisner DH. Abdominal ultrasound examination in pregnant blunt trauma patients. 7 Trauma 2001;50(4):689-93.

22. Corbett SW, Andrews HG, Baker EM, Jones WG. ED evaluation of the pediatric trauma patient by ultrasonography. $\mathrm{Am}$ 7 Emerg Med 2000;18(3):244-9.

23. Holmes JF, Brant WE, Bond WF, Sokolove PE, Kuppermann N. Emergency department ultrasonography in the evaluation of hypotensive and normotensive children with blunt abdominal trauma. I Pediatr Surg 2001;36 (7):968-73.

24. Fox JC, Boysen M, Gharahbaghian L, et al. Test characteristics of focused assessment of sonography for trauma for clinically significant abdominal free fluid in pediatric blunt abdominal trauma. Acad Emerg Med 2011 May;18(5):477-82.

25. Akgür FM, Aktuğ T, Kovanhkaya A, et al. Initial evaluation of children sustaining blunt abdominal trauma: ultrasonography vs. diagnostic peritoneal lavage. Eur 7 Pediatr Surg 1993;3 (5):278-80.

26. Coley BD, Mutabagani KH, Martin LC, et al. Focused abdominal sonography for trauma (FAST) in children with blunt abdominal trauma. 7 Trauma 2000;48(5):902-6.

27. Thourani VH, Pettitt BJ, Schmidt JA, Cooper WA, Rozycki GS. Validation of surgeon-performed emergency abdominal ultrasonography in pediatric trauma patients. $\mathcal{F}$ Pediatr Surg 1998;33(2):322-8.

28. Holmes JF, Harris D, Battistella FD. Performance of abdominal ultrasonography in blunt trauma patients with out-of-hospital or emergency department hypotension. Ann Emerg Med 2004;43(3):354-61.

29. Miller MT, Pasquale MD, Bromberg WJ, Wasser TE, Cox J. Not so FAST. 7 Trauma 2003;54(1):52-9.

30. Richards JR, McGahan PJ, Jewell MG, et al. Sonographic patterns of intraperitoneal hemorrhage associated with blunt splenic injury. 7 Ultrasound Med 2004;23(3):387-94.

31. Hsu JM, Joseph AP, Tarlinton LJ, Macken L, Blome S. The accuracy of focused assessment with sonography in trauma (FAST) in blunt trauma patients: experience of an Australian major trauma service. Injury 2007;38(1):71-5.

32. Röthlin MA, Näf R, Amgwerd M, et al. Ultrasound in blunt abdominal and thoracic trauma. $\mathcal{F}$ Trauma 1993;34 (4):488-95.

33. Kumar S, Bansal VK, Muduly DK, et al. Accuracy of focused assessment with sonography for trauma (FAST) in blunt trauma abdomen-a prospective study. Indian 7 Surg 2015;77 (S2 Suppl 2):393-7.

34. Ingeman JE, Plewa MC, Okasinski RE, King RW, Knotts FB. Emergency physician use of ultrasonography in blunt abdominal trauma. Acad Emerg Med 1996;3(10):931-7. 
35. Cheung KS, Wong HT, Leung LP, Tsang TC, Leung GK. Diagnostic accuracy of Focused Abdominal Sonography for Trauma in blunt abdominal trauma patients in a trauma centre of Hong Kong. Chin 7 Traumatol 2012;15(5):273-8.

36. Matsushima K, Khor D, Berona K, et al. Double jeopardy in penetrating trauma: Get FAST, get it right. World 7 Surg 2018;42(1):99-106.

37. Massarutti D, Berlot G, Saltarini M, et al. Abdominal ultrasonography and chest radiography are of limited value in the emergency room diagnostic work-up of seven trauma patients with hypotension on the scene of accident. Radiol Med 2004;108(3):218-24.

38. Gaarder C, Kroepelien CF, Loekke R, et al. Ultrasound performed by radiologists-confirming the truth about FAST in trauma. F Trauma 2009;67(2):323-7.

39. Lentz KA, McKenney MG, Nuñez Jr DB, Martin L. Evaluating blunt abdominal trauma: role for ultrasonography. $\mathcal{Z}$ Ultrasound Med 1996;15(6):447-51.

40. Kirkpatrick AW, Sirois M, Laupland KB, et al. Prospective evaluation of hand-held focused abdominal sonography for trauma (FAST) in blunt abdominal trauma. Can 7 Surg 2005;48(6):453-60.

41. Volpicelli G. Sonographic diagnosis of pneumothorax. Intensive Care Med 2011;37(2):224-32.

42. Soult MC, Weireter LJ, Britt RC, et al. Can routine trauma bay chest x-ray be bypassed with an extended focused assessment with sonography for trauma examination? Am Surg 2015;81(4):336-40.

43. Ianniello S, Di Giacomo V, Sessa B, Miele V. First-line sonographic diagnosis of pneumothorax in major trauma: accuracy of e-FAST and comparison with multidetector computed tomography. Radiol Med (Torino) 2014;119 (9):674-80.

44. Mumtaz U, Zahur Z, Chaudhry MA, Warraich RA. Bedside ultrasonography: A useful tool for traumatic pneumothorax. 7 Coll Physicians Surg Pak 2016;26(6):459-62.

45. Ojaghi Haghighi SH, Adimi I, Shams Vahdati S, Sarkhoshi Khiavi R. Ultrasonographic diagnosis of suspected hemopneumothorax in trauma patients. Trauma Mon 2014;19(4): e17498. 